\title{
Fatores ambientais e climáticos associados à ocorrência de Aedes aegypti
}

\author{
Environmental and climatic factors associated with the Aedes aegypti occurrence
}

Factores ambientales y climáticos asociados con la ocurrencia de Aedes aegypti

Recebido: 21/07/2021 | Revisado: 25/07/2021 | Aceito: 26/07/2021 | Publicado: 02/08/2021

Fabíola Inês Salvi

ORCID: https://orcid.org/0000-0003-0231-9448 Universidade Comunitária da Região de Chapecó, Brasil

E-mail: fabiola.salvi@unochapeco.edu.br

Maria Assunta Busato

ORCID: https://orcid.org/0000-0003-0043-7037 Universidade Comunitária da Região de Chapecó, Brasil E-mail: assunta@unochapeco.edu.br

Walter Antônio Roman Júnior

ORCID: https://orcid.org/0000-0001-8363-8795 Universidade Comunitária da Região de Chapecó, Brasil E-mail: romanwa@unochapeco.edu.br

Arnildo Korb

ORCID: https://orcid.org/0000-0001-7333-0754 Universidade Comunitária da Região de Chapecó, Brasil E-mail: arnildo.korb@udesc.br

Junir Antonio Lutinski

ORCID: https://orcid.org/0000-0003-0149-5415 Universidade Comunitária da Região de Chapecó, Brasil E-mail: junir@unochapeco.edu.br

\begin{abstract}
Resumo
A infestação pelo mosquito Aedes aegypti e a transmissão das patologias associadas como a Dengue, Zika Vírus e Febre Chikungunya tem sido um problema de saúde pública no Brasil e no mundo. A relação entre fatores ambientais e climáticos e a infestação por $A$. aegypti tem demonstrando especificidades regionais, alertando os profissionais de saúde na adoção de estratégias de prevenção e controle. Diante do exposto, o presente estudo teve como objetivo avaliar a relação entre os fatores ambientais e climáticos com a flutuação da população do vetor no município de Chapecó, Santa Catarina. Dados climáticos de temperatura mínima mensal, média mensal e máxima mensal, umidade relativa do ar média mensal, pressão atmosférica média mensal e pluviosidade total mensal foram obtidos junto à EPAGRI /CIRAM e correlacionados com a frequência de focos do vetor. Observou-se que a infestação não é espacialmente homogênea e que o tipo do imóvel, o tipo de criadouro, a pluviosidade mensal, a temperatura média e a umidade relativa do ar média mensal apresentaram significância $(\mathrm{p}<0,05)$ como determinantes da frequência dos focos. Observa-se a necessidade de adoção de estratégias de prevenção e de controle que considerem o sinergismo de fatores atuando sobre a população do vetor.
\end{abstract}

Palavras-chave: Dengue; Meteorologia; Pluviosidade; Temperatura.

\begin{abstract}
Infestation by the Aedes aegypti mosquito and transmission of associated pathologies such as Dengue fever, Zika virus and Chikungunya fever has been a public health problem in Brazil and in the world. The relationship between environmental and climatic factors and $A$. aegypti infestation has demonstrated regional specificities, alerting health professionals in the adoption of prevention and control strategies. In view of the above, the present study aimed to evaluate the relationship between environmental and climatic factors with the vector population fluctuation in the municipality of Chapecó, Santa Catarina. Climatic data of monthly minimum, monthly average and monthly maximum temperature, monthly relative humidity, mean monthly atmospheric pressure and monthly total rainfall were obtained from EPAGRI / CIRAM and correlated with the frequency of vector focuses. It was observed that the infestation is not spatially homogeneous and that the type of the property, the type of breeding place, the monthly rainfall, the average temperature and the relative humidity of the air presented significance $(\mathrm{p}<0.05)$ as determinants of the frequency of the focuses. It is observed the need to adopt prevention and control strategies that consider the synergism of factors acting on the vector population.
\end{abstract}

Keywords: Dengue; Meteorology; Rainfall; Temperature.

\section{Resumen}

La infestación por el mosquito Aedes aegypti y la transmisión de patologías asociadas como el dengue, el virus Zika y la fiebre chikungunya ha sido un problema de salud pública en Brasil y en todo el mundo. La relación entre factores 
ambientales y climáticos y la infestación de $A$. aegypti ha mostrado especificidades regionales, alertando a los profesionales de la salud en la adopción de estrategias de prevención y control. Dado lo anterior, este estudio tuvo como objetivo evaluar la relación entre factores ambientales y climáticos con la fluctuación de la población de vectores en el municipio de Chapecó, Santa Catarina. Los datos climáticos de mínimo mensual, promedio mensual y máximo mensual, humedad relativa promedio mensual, presión atmosférica promedio mensual y precipitación total mensual se obtuvieron de EPAGRI / CIRAM y se correlacionaron con la frecuencia de brotes de vectores. Se observó que la infestación no es espacialmente homogénea y que el tipo de predio, tipo de criadero, precipitación mensual, temperatura promedio y humedad relativa promedio mensual fueron significativos ( $\mathrm{p}<0.05)$ como determinantes de la frecuencia de los brotes. Es necesario adoptar estrategias de prevención y control que consideren el sinergismo de los factores que actúan sobre la población de vectores.

Palabras clave: Dengue; Meteorología; Lluvia; Temperatura.

\section{Introdução}

O mosquito Aedes aegypti (Linneaus, 1762) (Diptera: Culicidae) é uma espécie sinantrópica e antropofílica, com preferência e facilidade de proliferar em áreas urbanas densamente povoadas (Oliveira, 2015; Zara et al., 2016). O potencial patogênico desse inseto provém da capacidade de hospedar arbovírus, uma classe viral que possui, aproximadamente, 545 espécies, dessas, 150 podem causar patologias ao ser humano (Lopes, Nosawa \& Linhares, 2014). Entre as doenças causadas por esses vírus estão a Dengue, Febre Amarela, Zika Vírus e da Febre Chikungunya. A infestação pelo mosquito e, consequentemente, a transmissão das patologias associadas, em especial a Dengue, tem sido um problema de saúde pública desde o início do século XX, agravando-se a partir de 2014 pela introdução do Zika Vírus e da Febre Chikungunya no Brasil, e recentemente com a reurbanização da Febre Amarela nos anos de 2016 e 2017 (Cavalcante \& Tauil, 2016; Johansen, Carmo \& Alves, 2016).

A presença de A. aegypti é multifatorial e uma gama de fatores atuam conjuntamente proporcionando condições favoráveis para sobrevivência e manutenção da população do vetor, o que torna seu controle um desafio (Sanabria et al., 2017). Dentre as principais causas destacam-se as condições climáticas (temperatura, umidade, regimes regionais de precipitação e variações atmosféricas), socioeconômicos (condições de saneamento, coleta de resíduos sólidos deficiente, ausência de rede de água potável e tratamento de efluentes, baixas condições de renda) e fatores relacionados ao aumento da probabilidade de contato entre o vetor e o hospedeiro em um episódio epidêmico (proximidade das habitações, fluxo populacional, aumento e a rapidez das viagens intercontinentais) (Ribeiro, 2015). O carácter multifatorial é influenciado por características regionais, onde a diversidade de cenários e diferentes combinações dos fatores determinam a manutenção ou aumento da população do vetor.

Geograficamente, A. aegypti está presente em grande parte das regiões tropicais e subtropicais da África, Ásia, Américas e Oceania, onde temperatura, umidade relativa do ar e pluviosidade são mais altas que no resto do planeta (Oliveira \& 2015; Ribeiro, 2015). A relação entre fatores ambientais como tipos de imóveis e tipos de criadouros e climáticos como temperatura, pluviosidade e umidade relativa do ar com a infestação por A. aegypti tem sido relatada na última década, demonstrando regionalidade (Gomes, Nobre \& Cruz, 2012; Budnik et al., 2019). Segundo Oliveira (2015), variáveis climáticas locais podem ampliar conhecimentos sobre as particularidades de cada região, gerando maiores informações sobre sazonalidades e contribuir para aprimorar os mecanismos de predição de possíveis epidemias, visto que a relação vetor-clima se mostra tão ou até mais importante que a relação vetor-ser humano.

O Brasil possui diversos cenários climáticos, e por isso da necessidade de estudos que ilustrem a realidade local/regional. Embora existam inúmeros estudos acerca da biologia e padrões de infestação por A. aegypti (Beserra et al., 2010; Oliveira, 2015), desses, poucos abordam as características regionais e locais e suas interferências junto às populações do vetor. Estudos nessa perspectiva envolvendo a região oeste de Santa Catarina são ainda mais escassos e pontuais, dentre eles destaca-se o estudo conduzido Busato et al. (2014), que apontou que a maior infestação do vetor ocorre no período entre 
outubro e maio, coincidindo com os maiores índices de temperaturas e pluviosidade. Diante do exposto, o presente estudo teve como objetivo avaliar a relação entre os fatores ambientais e climáticos com a flutuação da população do vetor no município de Chapecó, Santa Catarina, no período de 2012 a 2016.

\section{Metodologia}

Trata-se de um estudo quantitativo, descritivo e retrospectivo, baseado em fontes secundárias de dados (Yin, 2015). Este estudo teve como referência geográfica o município de Chapecó (SC), localizado na região oeste de Santa Catarina (Latitude: $27^{\circ} 05^{`} 47^{\prime}$ ' S; Longitude: $52^{\circ} 37^{\prime} 06^{\prime}$ W), altitude de 674 metros. O município possui área territorial de 626,06 km², população estimada em 216.654 habitantes e área urbana de $113,2 \mathrm{~km}^{2}$, aproximadamente. Possui clima mesotérmico, temperatura média variável de 15 a $25^{\circ} \mathrm{C}$, umidade relativa do ar média aproximada de $73 \%$ (Alvares et al., 2014).

Os dados referentes aos registros de focos do vetor (criadouros positivos para a presença de A. aegypti nas formas de larva, pupa ou mosquito adulto) no período de 2012 a 2016 foram obtidos na forma de planilhas geradas pelo banco de dados do Programa Municipal de Combate a Dengue (PMCD). Foram utilizados dados referentes à frequência mensal e anual dos focos de A. aegypti segundo a ocorrência em imóveis por tipo, criadouros por tipo e região do município no período de 2012 a 2016. A categorização destes dados seguiu a nomenclatura utilizada pelo PNCD onde os tipos de imóveis são residenciais, comerciais, terrenos baldios (TB) e pontos estratégicos (PE) que, segundo descrito no PNCD, são estabelecimentos que contêm vários potenciais criadouros para o mosquito. Os tipos de criadouros são A1: criadouros elevados: caixas d'água e calhas; A2: criadouros ao nível de solo: cisternas, tonéis e similares; B: móveis: pratos de flores, bebedouros de animais, recipientes de degelo de geladeira e similares; C: fixo: piscinas, tanques em obras, calhas, ralos; D1: pneus e materiais rodantes; D2: passíveis de remoção: materiais descartáveis, garrafas, latas e similares; E: naturais: folhagens, bromélias e similares. Os dados referentes às variações climáticas da temperatura mínima mensal, média mensal e máxima mensal, umidade relativa do ar média mensal, pressão atmosférica média mensal e pluviosidade total mensal, no período 2012 a 2016, foram obtidos junto ao Centro de Informações de Recursos Ambientais e de Hidrometeorologia de Santa Catarina/Empresa de Pesquisa Agropecuária e Extensão Rural de Santa Catarina (CIRAM/EPAGRI) também em forma de planilhas.

Para avaliar a distribuição espacial dos focos, segundo os bairros, aplicou-se uma análise de ordenação Non-metric Multidimensional Scaling (NMDS) com base na frequência mensal dos focos do vetor em cada bairro. A matriz dos dados foi previamente transformada em $\log (x+1)$, foi utilizado Bray-Curtis como índice de associação e a análise foi realizada com o programa estatístico Primer 6.1.9.

Para verificar a associação da frequência mensal de focos, segundo o tipo de imóvel e tipo de criadouro, adotou-se Análises de Componentes Principais (PCA). Para tal, utilizou-se o programa PAST. E, para avaliar a influência dos fatores climáticos sobre os registros de focos ao longo dos meses segundo o tipo de criadouro e tipo de imóvel, efetuou-se Análise de Correspondência Canônica (CCA). Esta análise foi obtida com auxílio do programa Canoco for Windows.

Este estudo atendeu as determinações da Resolução 466/2012 da Comissão Nacional de Ética e Pesquisa com Seres Humanos sendo aprovado (Conselho Nacional de Saúde, 1996) e foi previamente aprovado sob parecer número 2.323.038.

\section{Resultados}

A distribuição espacial dos focos mostrou similaridade de 35\% quanto à composição e frequência nos bairros estudados, a citar: Alvorada, Bela Vista, Bom Pastor, Centro, Cristo Rei, Engenho Braun, Esplanada, Jardim América, Jardim Itália, Líder, Maria Goretti, Palmital, Paraíso, Parque das Palmeiras, Passo do Fortes, Pinheirinho, Presidente Médice, Quedas do Palmital, Saic, Santa Maria, Santo Antônio, São Pedro, Universitário e Vila Rica (formaram um conjunto da NMDS. Os bairros Belvedere, Marechal Bormann, Seminário e Boa Vista formaram um segundo grupo. Porém, os bairros Efapi e São 
Cristovão formaram um grupo menor e os bairros Eldorado, Santa Paulina, Trevo e Vila Rica foram ordenados individualmente (Figura 1).

Figura 1- Análise de ordenação pelo método Non-metric Multidimensional Scaling (NMDS) para distribuição espacial dos focos registrados no município de Chapecó-SC no período de 2012 a 2016.

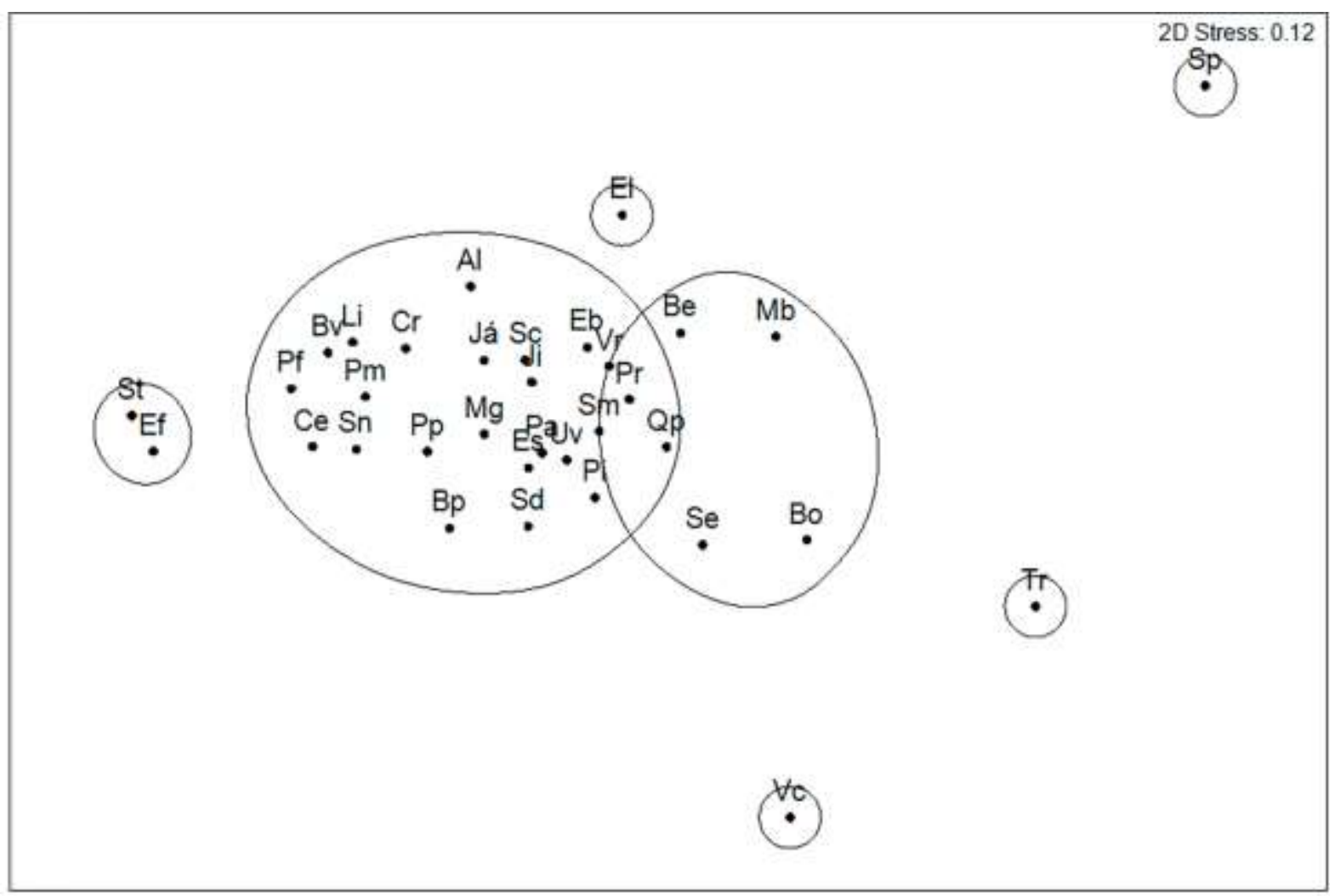

Legenda: Alvorada (Al), Bela Vista (Bv), Belvedere (Be), Boa Vista (Bo), Bom Pastor (Bp), Centro (Ce), Cristo Rei (Cr), Efapi (Ef), Engenho Braun (Eb), Eldorado (El), Esplanada (Es), Jardim América (Já), Jardim Itália (Ji), Líder (Li), Marechal Bormann (Mb), Maria Goretti (Mg), Palmital (Pa), Paraíso (Pr), Parque das Palmeiras (Pp), Passo do Fortes (Pf), Pinheirinho (Pi), Presidente Médice (Pm) Quedas do Palmital (Qp), Saic (Sc), Santa Maria (Sm), Santa Paulina (Sp), Santo Antônio (Sn), São Cristovão (St), São Pedro (Sd), Seminário (Se), Trevo (Tr), Universitário (Uv), Vila Real (Vr), Vila Rica (Vc).

Fonte: Autores.

Quanto à ocorrência mensal de focos por tipo de imóveis, houve maior contribuição de pontos estratégicos (PE) e comércios. Observou-se similaridade entre residências e comércios quanto à frequência mensal dos focos. A menor frequência de focos foi em terrenos baldios (TB). Ao todo, 87,3\% da variação dos focos, segundo o tipo de imóvel, foi explicado pelos eixos 1 e 2 da Análise de Componentes Principais (PCA) (Figura 2). 
Figura 2 - Ordenação pelo método de Análise de Componentes Principais (PCA) da ocorrência mensal de focos, segundo o tipo imóvel, município de Chapecó-SC, período de 2012 a 2016.

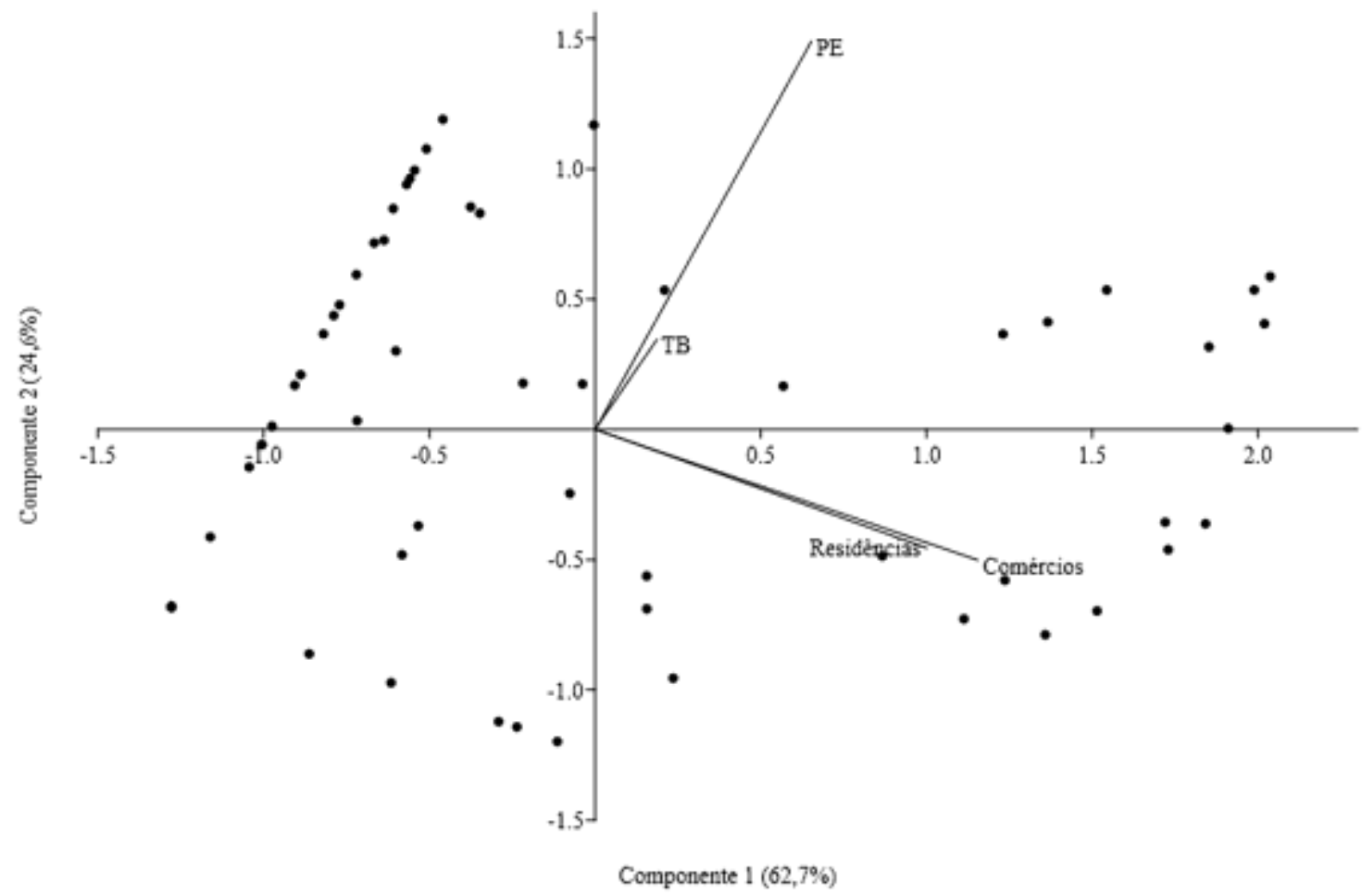

Legenda: Pontos representam a frequência dos focos nos 60 meses avaliados, PE pontos estratégicos, TB terrenos baldios. Fonte: Autores.

Um total de 95,4\% da variação mensal dos focos, segundo o tipo de criadouros, foi explicada pelos eixos 1 e 2 da PCA. Criadouros D1 (pneus e materiais rodantes), D2 (passíveis de remoção: materiais descartáveis, garrafas, latas e similares) e C (fixo: piscinas, tanques em obras, calhas, ralos) foram os que mais se destacaram na análise. Focos em D1 e D2 apresentaram similaridade entre si quanto à distribuição e frequência ao longo dos meses avaliados. Resultado semelhante ocorreu entre criadouros A1(criadouros elevados: caixas d'água e calhas), C e E (naturais: folhagens, bromélias e similares) (Figura 3).

Sobre a influência dos fatores climáticos na ocorrência de focos segundo o tipo de imóvel e tipo de criadouro, observou-se que a pluviosidade mensal, a temperatura média e a umidade relativa do ar média mensal apresentaram significância como determinantes $(\mathrm{p}<0,05)$.

Observou-se que as duas últimas variáveis apresentaram maior relação. As temperaturas máximas e mínimas mensais não apresentaram significância na ordenação CCA. Contudo, apenas 13,6\% da variação foi explicada pelos eixos 1 e 2 da Ordenação de Correspondência Canônica (Figura 4). 
Figura 3 - Ordenação pelo método Análise de Componentes Principais (PCA) da ocorrência mensal de focos, segundo o tipo de criadouros, município de Chapecó-SC, período de 2012 a 2016.

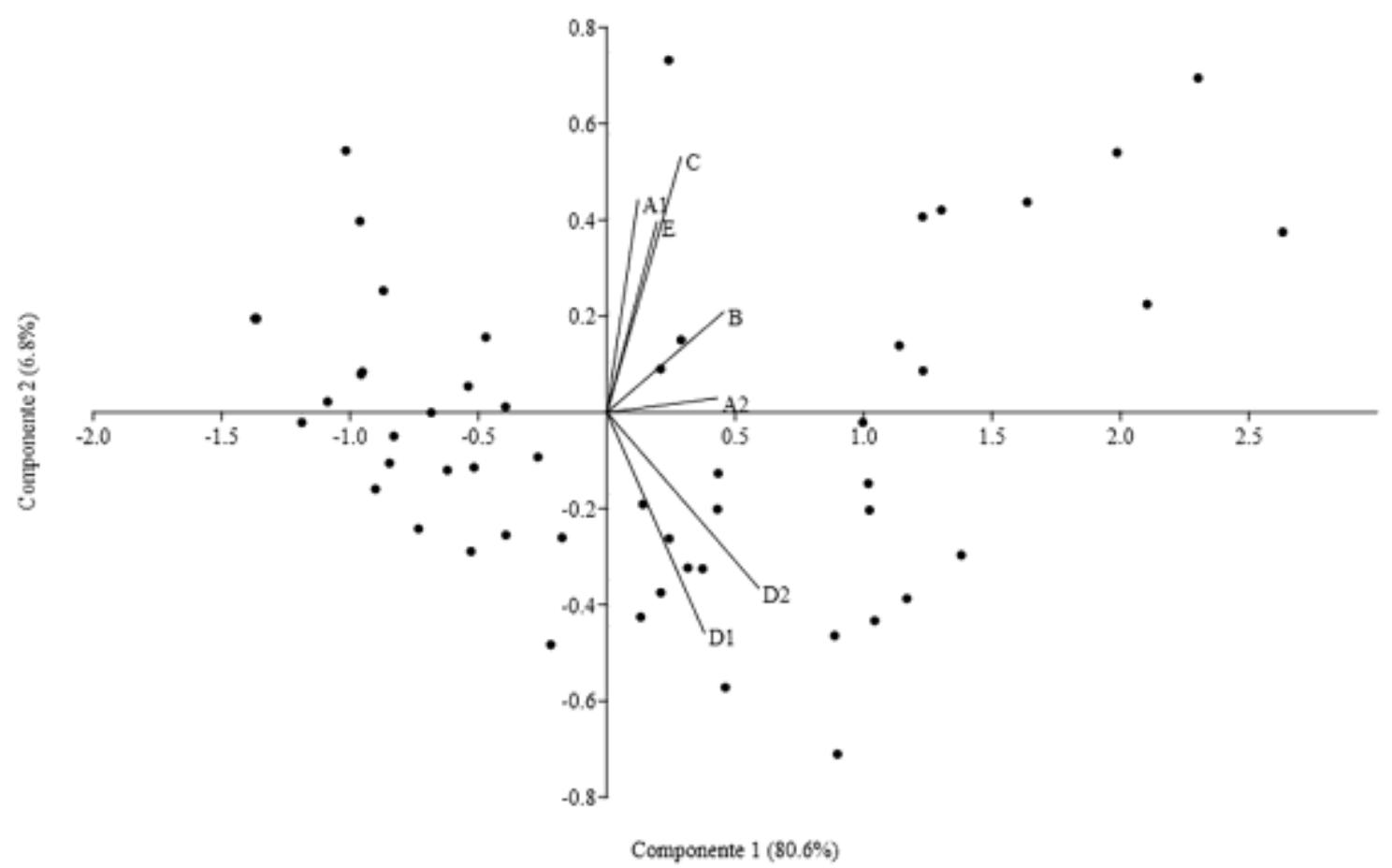

Legenda: A1: criadouros elevados: caixas d'água e calhas; A2: criadouros ao nível de solo: cisternas, tonéis e similares; B: móveis: pratos de flores, bebedouros de animais, recipientes de degelo de geladeira e similares; C: fixo: piscinas, tanques em obras, calhas, ralos; D1: pneus e materiais rodantes; D2: passíveis de remoção: materiais descartáveis, garrafas, latas e similares; E: naturais: folhagens, bromélias e similares. Fonte: Autores. 
Figura 4 - Ordenação pelo método de Correspondência Canônica (CCA) de focos mensais, segundo o tipo de criadouros, tipo de imóvel (PNCD), tendo dados climáticos ambientais como variáveis preditoras, município de Chapecó-SC, período de 2012 a 2016.

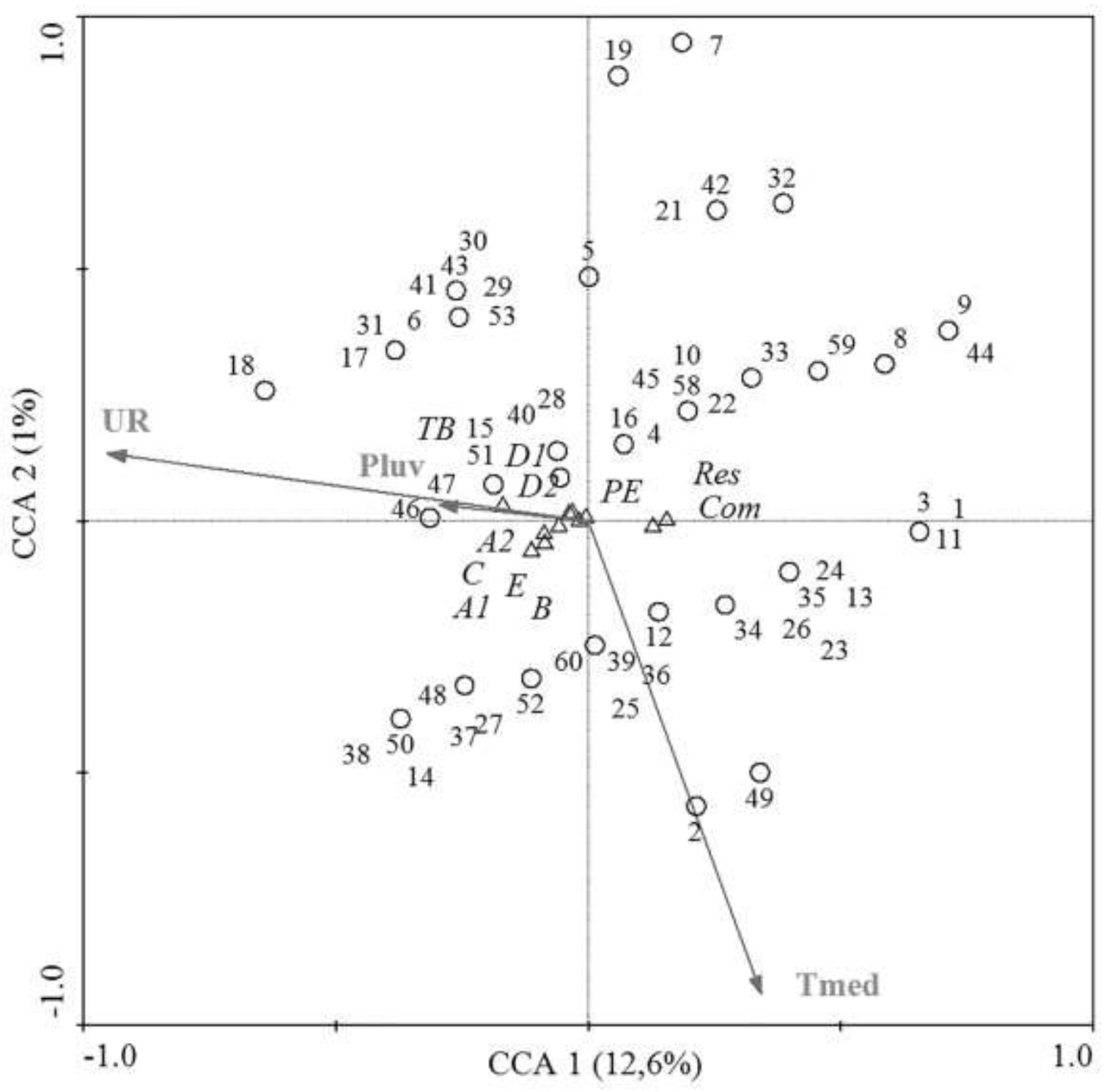

Legenda: Tmed: temperatura média mensal: UR: umidade relativa do ar média mensal; Pluv: pluviosidade média mensal; Res: residências; Com: comércio: PE: pontos estratégicos; TB: terrenos baldios; A1: criadouros elevados: caixas d'água e calhas; A2: criadouros ao nível de solo: cisterna, tonéis e similares; B: móveis: pratos de flores, bebedouros de animais, recipientes de degelo de geladeira e similares; C: fixo: piscinas, tanques em obras, calhas, ralos; D1: pneus e materiais rodantes; D2: passíveis de remoção: materiais descartáveis, garrafas, latas e similares; E: naturais: folhagens, bromélias e similares; pontos representam os meses do período estudado.

Fonte: Autores.

\section{Discussão}

A ocorrência de A. aegypti e de surtos e epidemiológicos são multicausais (Sanabria et al., 2017) e a diversidade de cenários para sobrevivência e disseminação do vetor é uma das características que desafiam o controle populacional. Tanto que a distribuição espacial dos focos do vetor mostrou heterogeneidade resultando em sete grupos distintos.

O primeiro e maior agrupamento de bairros, contendo 24, apresentava diferentes características socioeconômicas e geográficas. Nessa região estão inclusos bairros famílias com perfil de classe A (renda média familiar acima de 20 salários mínimos), B (renda de 10 a 20 salários mínimos) e C (renda de quatro a 10 salários mínimos), bairros periféricos com perfis de 
classe D (renda de dois a quatro salários mínimos) e E (renda de um a dois salários mínimos), o que sugere que a característica socioeconômica geral do bairro não é um dos fatores influenciadores da flutuação nas populações do vetor. Esse resultado corrobora com os achados de Oliveira \& Souza-Santos (2009) no município de Nova Iguaçu (RJ) e de Akter et al. (2017) e Álvarez Escobar et al. (2018) que relataram que a distribuição espacial da incidência de casos de Dengue ocorre de forma heterogênea no território.

Em um segundo agrupamento de bairros foram analisados os bairros Marechal Bormann (Mb), Belvedere (Be), Seminário (Se) e Boa Vista (Bo), localizados em torno de rodovias ou vias de acesso ao município, e que apresentam intenso fluxo de veículos. Esses quatro bairros também possuem indústrias e que intensificam esse fluxo de veículos, principalmente de caminhões. Machado, Oliveira \& Souza-Santos (2009), num estudo no município de Nova Iguaçu (RJ), perceberam maior incidência de Dengue em áreas em torno de vias de acesso e atribuíram o fato a presença de postos de gasolina, borracharias e ferros-velhos ao longo das principais vias de acesso, atividades econômicas associadas à presença de criadouros do vetor.

Os bairros Efapi (Ef) e São Cristovão (St), foram agrupados pela análise NMDS em um agrupamento menor. Apresentam similaridades quanto ao perfil socioeconômico, demográfico e territorial. Ambos, periféricos, são categorizados como bairros de classes D, possuem o mesmo perfil de moradias, comércios e indústrias. Não possuem rede de coleta de efluentes, e o abastecimento de água ocorre de forma intermitente em períodos com menores índices de pluviosidade, assim como a coleta de resíduos não é diária. Também, são os bairros com mais longo histórico e maior índice infestação pelo mosquito do município, configurando maior risco de disseminação das enfermidades transmitidas pelo vetor.

O abastecimento de água intermitente leva os moradores a construírem cisternas para armazenamento de água, não havendo tratamento prévio e assim como os resíduos sólidos depositados em locais impróprios, se tornam potenciais criadouros (Flauzino, Oliveira \& Souza-Santos, 2011). Ryan et al. (2019) apontaram que as condições de serviços e estruturas de saneamento básico são fatores determinantes para a instalação da Dengue assim como as condições socioeconômica em si. Almeida \& Silva (2018), em estudo nos municípios de João Pessoa, Cabedelo e Bayeux (Paraíba) no período de 2011 a 2014, atribuem a grande quantidade de resíduos sólidos expostos em vias públicas e a ineficácia do serviço de coleta e destinação destes resíduos como fator determinante para a proliferação do A. aegypti. Em bairros carentes, além das condições estruturais de saneamento público frágil, há carência nas condições de habitações. Em muitos casos, reservatórios de água são improvisados em recipientes sem proteção ou tampas (Flauzino, Oliveira \& Souza-Santos, 2011).

Pontos estratégicos são imóveis cujas características configuram ambientes propícios para a instalação do vetor e por isso podem apresentar maior número de focos. Frequentemente são locais que abrigam usinas de reciclagem, borracharias, desmontes de veículos, floriculturas, cemitérios e locais com entulhos desprotegidos. Esses imóveis são mapeados e vistoriados regularmente pelo PMCD, sendo assim esperado sua maior contribuição para o número de focos. A similaridade mensal dos registros de focos em residências e comércio corrobora com os achados de Silva (2017) no Estado de Santa Catarina, especialmente nos municípios de Florianópolis, Biguaçu, São José e Palhoça no período de 2007 a 2016, confirmando uma tendência para o Estado. Costa et al. (2016) relataram no município de Picos (PI), no período de 2007 a 2011, que os imóveis mais acometidos com focos são as residências e terrenos baldios, nesse caso justificado pela realidade local com precariedade nos serviços de saneamento, onde há necessidade de armazenamento de água potável em cisternas e os TB acabam se tornando locais de descarte de resíduos. Lutinski et al. (2013), ao traçarem um perfil da infestação do vetor no município de Chapecó no período de 2008 a 2012, relataram similaridade entre residências e ambientes comercias, porém no período analisado pelos autores os focos em residências foram mais frequentes, seguidos por comércio e TB, e PE. A modificação do perfil de tipo imóvel pode ser explicada pela intensificação das ações de vigilância ambiental adotadas pelo Programa municipal de Controle da Dengue para o monitoramento da infestação e da implementação de ações de prevenção ao mosquito como mutirões de limpeza de TB, que contribuíram para a diminuição dos focos nesse tipo de imóvel. 
Quanto aos tipos de depósitos, houve predominância dos grupos D1 (pneus e materiais rodantes removíveis) e D2 (entulho, sucata, recicláveis em geral e resíduos sólidos). Esse achado se deu pela quantidade de usinas de reciclagens e acúmulo de resíduos em residências, ambos em geral desprovidos de proteção contra o acúmulo de água. Os mesmos resultados foram obtidos por Fernandes et al. (2014) no município de Tangará da Serra (MT) no período de 2008 a 2010. Neste estudo, os depósitos foram relacionados com os casos de Dengue, havendo correlação positiva para depósitos D1 e D2. Costa et al. (2016) encontraram maior ocorrência de A. aegypti em depósitos do tipo A2 (reservatórios de água elevados). Realidade semelhante ao presente estudo foi também verificada por Silva (2017), em que os depósitos do tipo D2 foram mais frequentes.

Os resultados demonstram multicasualidade da infestação pelo vetor e sua capacidade de adaptação ao meio urbano. Depósitos D1 e D2 são historicamente os mais recorrentes, pois são resíduos descartáveis, refletindo em alguns casos a fragilidade dos serviços de coleta de resíduos e também a instalação das reciclagens como atividade econômica e fonte de renda para muitas famílias, multiplicando pontos de acúmulo destes materiais pela cidade. Já a maior ocorrência dos focos A2 indica precariedade no abastecimento de água potável à população.

O ciclo de vida dos vetores possui forte conexão com a dinâmica ambiental dos ecossistemas onde vivem (Budnik et al., 2019). Fatores ambientais e climáticos influenciam a ocorrência, dispersão e flutuação das populações do A. aegypti. No presente estudo, a temperatura média mensal se mostrou como um dos fatores que influenciam a flutuação da população do vetor no período estudado. Esse fato corrobora com os estudos de Beserra et al. (2010) e Weber \& Wollmann (2016). Estudos associando a temperatura com casos de Dengue comprovam correlação positiva entre essas variáveis, além de apontarem os meses de outubro a abril como o período com maior registro de casos de patologias relacionadas ao vetor (Gomes, Nobre \& Cruz, 2012; Ribeiro, 2015; Ferreira, Chiaravalloti Neto \& Mondini, 2018). Essa correlação é resultado da ação de temperaturas elevadas sobre a fecundidade, fertilidade e sobrevivência do A. aegypti. Beserra et al. (2010) avaliaram o efeito da temperatura sobre o ciclo de vida do vetor, além de determinar as exigências térmicas para o seu desenvolvimento. Os autores constataram que a taxa de crescimento e maturação de ovo, larva, pupa e da metamorfose ovo a adulto aumenta à medida que ocorre elevação da temperatura. Os resultados encontrados pelos autores também mostraram extremos de temperatura $\left(18{ }^{\circ} \mathrm{C}\right.$ e $\left.34^{\circ} \mathrm{C}\right)$ diminuem a atividade de oviposição, e temperaturas a partir dos $28{ }^{\circ} \mathrm{C}$ diminuem a longevidade do mosquito. Silva e Silva (2012) compilaram vários estudos que relacionam condições bioclimáticas e infestação pelo vetor no estado do Rio Grande do Norte, além de coletarem dados referente à temperatura e umidade relativa do ar. Relataram que valores extremos de temperatura (abaixo de $0{ }^{\circ} \mathrm{C}$ e acima de $40^{\circ} \mathrm{C}$ ) são letais ao mosquito; na faixa de $0{ }^{\circ} \mathrm{C}$ e $18{ }^{\circ} \mathrm{C}$ os espécimes se encontram em diapausa; na faixa de $18{ }^{\circ} \mathrm{C}$ e $21{ }^{\circ} \mathrm{C}$ e $34{ }^{\circ} \mathrm{C}$ e $40{ }^{\circ} \mathrm{C}$, os espécimes apresentam dificuldades de desenvolvimento; a faixa de 21 ${ }^{\circ} \mathrm{C}$ a $29{ }^{\circ} \mathrm{C}$ apresenta-se como favorável ao seu desenvolvimento; na faixa entre $29{ }^{\circ} \mathrm{C}$ e $32{ }^{\circ} \mathrm{C}$ ocorre potencialidade máxima de desenvolvimento do vetor; e a partir de $32{ }^{\circ} \mathrm{C}$ e $34{ }^{\circ} \mathrm{C}$ inicia-se declínio no potencial de desenvolvimento. Também, Tuladhar et al. (2019) demonstraram que a temperatura reduz a produção de ovos e de oviposição. A $25{ }^{\circ} \mathrm{C}, 80 \%$ das fêmeas dobraram sua longevidade e produziram $40 \%$ mais ovos que aquelas mantidas a $35^{\circ} \mathrm{C}$. A partir dos $35^{\circ} \mathrm{C}$ a atividade decai em média de $50 \%$ em todos os parâmetros citados. Os autores concluíram que a temperatura ótima para a reprodução e sobrevivência do vetor está entre $25^{\circ} \mathrm{C}$ e $35^{\circ} \mathrm{C}$, temperaturas essas recorrentes no período de novembro a março no município de Chapecó.

Da mesma forma a umidade relativa do ar também se mostrou um fator relevante para a flutuação da população do vetor no período estudado. Fêmeas mantidas à temperatura de $25^{\circ} \mathrm{C}$ e umidade de $80 \%$ sobreviveram duas vezes mais e produziram $40 \%$ mais ovos que aquelas mantidas a $35{ }^{\circ} \mathrm{C}$ e $80 \%$ de umidade. Constatou-se também que $45 \%$ das fêmeas mantidas a $35{ }^{\circ} \mathrm{C}$ e $60 \%$ de umidade tiveram a postura inibida. Weber \& Wollmann (2016) ao estudarem a influência dos fatores ambientais sobre as populações do vetor no município de Santa Maria (RS), também associaram positivamente a umidade relativa do ar com focos de A. aegypti, porém de forma discreta. Ao analisarem de forma conjunta temperatura média 
mensal e pluviosidade, os autores concluíram que a umidade relativa do ar é relevante para a disseminação do mosquito, principalmente quando acompanhada de altas temperaturas.

Embora com menor participação na explicação da variação dos focos no presente estudo, a pluviosidade também atua positivamente para a flutuação das populações do A. aegypti. Fato que corrobora com os achados de Ajus \& Vestena (2013), Weber \& Wollmann (2016). Da mesma forma, Cruz et al. (2015) e Ferreira, Chiaravalloti Neto \& Mondini (2018), todos os autores, associaram positivamente a pluviosidade com casos de Dengue. A pluviosidade age como facilitador por aumentar o aporte de possíveis depósitos para o vetor, além de atuar na eclosão dos ovos. Áreas com acúmulo de resíduos, sucatas e entulhos desprotegidos são bastante vulneráveis às intempéries e ao acúmulo de água, influenciando no crescimento populacional do vetor e nos casos de dengue.

\section{Conclusão}

Constatadas as devidas relações entre fatores ambientais e climáticos no desenvolvimento de focos e surtos de dengue na região analisada pontuamos que a distribuição espacial dos focos do vetor no município de Chapecó, SC no período de 2012 a 2016 não foi uniforme, assim com as infestações de A. aegypti, bem como a instalação de epidemias das patologias transmitidas, são processos multicausais.

Também se observou que a infestação varia conforme do tipo de imóvel, sendo os PE e comércios os que mais contribuíram para proliferação do vetor. Em relação ao tipo de criadouros, observou-se também variação conforme o tipo em que D1, D2 e C foram os mais frequentes. Esse resultado aponta a necessidade de atenção dos gestores de saúde para a adoção de estratégias de eliminação e de controle voltadas para cada tipo de criadouro e para cada tipo de imóvel.

Estes resultados demostram a diversidade de cenários ambientais e climáticos que interagem entre si de forma dinâmica no território e no tempo sobre a flutuação das populações do vetor. Nesse sentido, é fundamental ser explorado estes cenários, compilando dados referente aos principais fatores influenciadores e das doenças transmitidas pelo vetor, analisando seus pormenores e traçando um perfil detalhado da realidade local.

\section{Agradecimentos}

À Universidade Comunitária de Região de Chapecó (Unochapecó), pela concessão de bolsa de estudo institucional integral conforme a Resolução 60/2017 e à Fundação de Amparo à Pesquisa e Inovação de Santa Catarina (FAPESC) pela concessão de bolsa de estudo conforme o artigo 171/CE (UNIEDU). À Empresa de Pesquisa Agropecuária e Extensão Rural de Santa Catarina (EPAGRI/CIRAM SC) pela disponibilização e autorização de uso dos dados climáticos.

\section{Referências}

Ajus, L. C., \& Vestena, L. R. (2013). Influência da pluviosidade e temperatura ambiente na longevidade e fecundidade dos Aedes aegypti e albopictus na cidade de Guarapuava-PR e possibilidade de superinfestação. Hygeia. 10(18), 1-18.

Akter, R., Naish, S., Hu, W., \& TONG, S. (2017). Socio-demographic, ecological factors and dengue infection trends in Australia. PLoS One. 12(10: e0185551), 1-18.

Almeida, C. A. P., \& SILVA, R. M. da. (2018). Análise da ocorrência dos casos de dengue e sua relação com as condições socioambientais em espaços urbanos: os casos de João Pessoa, Cabedelo e Bayeux, no estado da Paraíba - Brasil. Hygeia. 14(27), 56-79.

Álvarez Escobar, M. C., Torres Álvarez, A., Torres Álvarez, A., Semper, A. I., \& Romeo Almanza, D. (2018). Dengue, chikungunya, Virus de Zika. Determinantes sociales. Revista Médica Electrónica. 40(1), 120-128.

Alvares, C. A., Stape, J. L., Sentelhas, P. C., Gonçalves, J. L. M., \& Sparovek, G. (2014). Köppen's climate classification map for Brazil. Meteorologische Zeitschrift. 22(6), 711-728.

Beserra, E. B., Fernandes, C. R. M., Sousa, J. T., Freitas, E. M., \& Santos, K. D. (2010). Efeito da qualidade da água no ciclo de vida e na atração para oviposição de Aedes aegypti (L.) (Diptera: Culicidae). Neotropical Entomology. 39(6), 1016-1023. 
Budnik, L. T., Casteleyn, L., Paschalidou, A. K., \& Kassomenos, P. (2019). Pollution in living and working environments, climate variability, and their impact on non-communicable disease burden. Science of the total environment. 660(10), 593-594.

Busato, M. A., Corralo, V. S., Guarda, C., Zulian, V., Lutinski, J. A., \& Bordin, S. M. S. (2014). Evolução da infestação por Aedes aegypti (Diptera: Culicidae) nos municípios do oeste do estado de Santa Catarina. Revista Saúde Pública Santa Catarina. 7(2), $107-118$.

Cavalcante, K. R. L. J., \& Tauil, P. L. (2016). Características epidemiológicas da febre amarela no Brasil, 2000-2012. Epidemiologia e Serviços de Saúde, Brasília. 25(1), 11-20.

Costa, A. R., Santana, C. M., Silva, V. L., Pinheiro, J. A. F., Marques, M. M. M., \& Ferreira, P. M. P. (2016). Análise do controle vetorial da dengue no sertão piauiense entre 2007 e 2011. Cadernos de Saúde Coletiva. 24(3), 275-281.

Cruz, N. L. N., Lima, V. F. S., Silva, E. M. DA, \& Ramos, J. V. DE A. (2015). Epidemiologia da dengue e sua relação com a variabilidade climatológica no município de Igarassu, Pernambuco, Brasil. Hygeia. 11(21), 107-115.

Fernandes, R. S., Neves, S. M. A. DA S., Pereira, M. J. B., Ignotti, E., \& Souza, C. K. J. (2014). Dengue e fatores ambientais no município de Tangará da Serra, Amazônia Brasileira. Boletim de Geografia. 32(1), 35-51.

Ferreira, A. C., Chiaravalloti Neto, F., \& Mondini, A. (2018). Dengue em Araraquara, SP: epidemiologia, clima e infestação por Aedes aegypti. Revista Saúde Pública. 52(18), 1-10.

Flauzino, R. F., Oliveira, R. M., \& Souza-Santos, R. (2011). .Indicadores socioambientais para vigilância da Dengue em nível local. Saúde e Sociedade. 20(1), $225-240$.

Gomes, Nobre, A. A., \& Cruz, O. G. (2012). Análise temporal da relação entre dengue e variáveis meteorológicas na cidade do Rio de Janeiro, Brasil, no período de 2001 a 2009. Cadernos de Saúde Pública. 28(11), 2189-2197.

Johansen, I. C., Carmo, R. L. do, \& Alves, L. C. (2016). Desigualdade social intraurbana: implicações sobre a epidemia de dengue em Campinas, SP, em 2014. Cadernos Metrópole. 18(36), 421-440.

Lopes, N., Nosawa, C., \& Linhares, R. E. C. (2014). Características gerais e epidemiologia dos arbovírus emergentes no Brasil. Revista Pan-Amazônica de Saúde. 5(3), 55-64.

Lutinski, J. A., Zanchet B., Guarda, C., Constanci, C., Friedrich, D. V., Cechin, F. T. C., Bones, I. A., Souza, M. F., Balsan, S. T., Zarychta, S. M., \& Busato, M. A. (2013). Infestação pelo mosquito Aedes aegypti (Diptera: Culicidae) na cidade de Chapecó-SC. Revista Biotemas. 26(2), 143-151.

Machado, J. P., Oliveira, R. M., \& Souza-Santos, R. (2009). Análise espacial da ocorrência de dengue e condições de vida na cidade de Nova Iguaçu, Estado do Rio de Janeiro, Brasil. Cadernos de Saúde Pública. 25(5), 1025-1034.

Oliveira, R. L. (2015). Biologia e comportamento do vetor. In: Valle, D., Pimenta, D. N., \& Cunha, R. V. (Org.). Dengue: teorias e práticas. Rio de Janeiro: Editora Fiocruz.

Ryan, S. J., Lippi, C. A., Nightingale, R., Hamerlinck, G., Borbor-Cordova, M. J., Cruz, B. M., Ortega, F., Leon, R., Waggoner, E., \& Stewart-Ibarra, A. M. (2019). Socio-Ecological Factors Associated with Dengue Risk and Aedes aegypti Presence in the Galápagos Islands, Ecuador. International Journal of Environmental Research and Public Health. 16(5), 2-26.

Ribeiro, M. D. (2015). Estudo descritivo da ocorrência de dengue e sua relação com o clima e a ação da vigilância em saúde do município de Franca, São Paulo, Brasil, 2007 a 2011. Revista Investigação Saúde. 14(1), 138-144.

Sanabria, E, Rodriguez, N, Samudio, M, Martínez, N, TORALES, M, \& AGUAYO, N. (2017). Criaderos de Aedes aegypti en la ciudad de Asunción, Paraguay durante los años 2011-2014 / Aedes aegypti breeding site in the city of Asunción, Paraguay in the 2011-2014 periods. Revista de salud pública del Paraguay. 7(1), 33-36.

Silva, C. P. (2017). Aspectos epidemiológicos da infestação por Aedes aegypti (Diptera: Culicidae) nos municípios de Florianópolis, São José, Biguaçu e Palhoça e comparação com a situação do estado de Santa Catarina. 2017. 76 f. Trabalho de Conclusão de Curso (Graduação em Ciências Biológicas) Universidade Federal de Santa Catarina, Florianópolis.

Silva, L. C., \& Silva, R. D. da. (2012). Percepção ambiental dos moradores da área Conjunto Cidadão e a relação com os casos de Dengue no bairro Senador Hélio Campos, Boa Vista-RR. Revista Norte Científico. 7(1), 140-150.

Tuladhar, R., Singh, A., Banjara, M. R., Gautam, I., Dhimal, M., Varma, A., \& Choudhary, D. K. (2019). Effect of meteorological factors on the seasonal prevalence of dengue vectors in upland hilly and lowland Terai regions of Nepal. Parasites \& Vectors. 12(1), 1-15.

Weber, A. A., \& Wollmann, C. A. (2016). A influência climática na proliferação do mosquito Aedes aegypti em Santa Maria - RS, em 2012. Ciência e Natura. 38(3), 1246-1253.

Yin, R.K. (2015). O estudo de caso. Porto Alegre: Bookman.

Zara, A. L. de S. A., Santos, S. M., Fernandes-Oliveira, E. S., Carvalho, R. G., \& Coelho, G. E. (2016). Estratégias de controle de Aedes aegypti: uma revisão. Epidemiologia e Serviços de Saúde. 25(2), 391-404. 